\title{
Mobile-Assisted Mind Mapping (MAMMAT) as a Tool to Support University Students' Argumentative Writing
}

\author{
https://doi.org/10.3991/ijim.v15i05.14003 \\ Rafidah Abd Karim ${ }^{(凶)}$ \\ Universiti Teknologi MARA, Perak, Malaysia \\ feida16@uitm.edu.my \\ Airil Haimi Mohd Adnan \\ Universiti Teknologi MARA, Selangor, Malaysia \\ Abdul Ghani Abu \\ Universiti Pendidikan Sultan Idris, Perak, Malaysia \\ Noorzaina Idris \\ Universiti Teknologi MARA, Selangor, Malaysia \\ Izwah Ismail \\ Politeknik Ungku Omar, Ipoh, Malaysia
}

\begin{abstract}
This study focuses on a technological tool known as the Mobileassisted Mind Mapping Technique (MAMMAT). This tool was designed and developed as a mobile application to deliver essential course contents employing online mind mapping to support argumentative writing skill performance. The primary purpose of this study was to determine the effects of MAMMAT on English as a Second Language (ESL) university students in Malaysia. The participants of this study were $45 \mathrm{ESL}$ university students from two lecture groups at a public university campus in Malaysia. The study employed a quasiexperimental research design. The experimental group was taught with the MAMMAT while the control group was taught using the conventional method. The pre-test and post-test scores were analyzed through the analysis of covariance (ANCOVA). Based on the ANCOVA results, the mean score of post-tests for the MAMMAT on the experimental group was higher than the mean of post-tests on the control group in terms of argumentative writing performance. Therefore, the MAMMAT was found to be effective in enhancing the argumentative writing performance of ESL university students. MAMMAT supports and enhances ESL university students' argumentative writing skills performance through innovative use of mobile technology, and this technique shows potential not just for second language learners of English in Malaysia but in other countries as well.
\end{abstract}

Keywords - Mobile-assisted Mind Mapping Technique, ESL university students, argumentative writing, mobile-based technological tool 


\section{Introduction}

Mobile devices offer exceptional features and develop a new trend of teaching and learning [1]. Mobile learning is mainly about e-learning which uses mobile devices to transform learning environments in positive ways. Hence, Mobile-Assisted Language Learning (MALL) has come into being as a new multidisciplinary field of educational technology. MALL has increased its popularity among students and educators due to the widespread use of various mobile technologies to enhance learning. Previous studies have shown that $98.75 \%$ of students have access to 'smartphones' [2]. As a result, many now prefer to use mobile devices than traditional desktop computers for their daily online tasks, including for teaching and learning [3]. MAMMAT or the Mobile-Assisted Mind Mapping Technique is a supportive teaching and learning platform which delivers essential course contents using online mind mapping to improve argumentative writing skill performance. This mobile-based technological tool is a supportive learning platform which contains some essential components of learning course contents and innovative technique using online mind mapping in improving argumentative writing skill performance for ESL university students. This tool is to assist ESL university students to brainstorm ideas, provide reasons and give evidence in their argumentative writing process, to help students to construct arguments and reasoning ability for argumentative writing skill and, to develop critical thinking skills and improve critical thinking ability. In addition, several studies have shown how mobile applications can impart online mind mapping technique to diploma students and to other students in other Malaysian higher educational institutions (HEIs) [4].

Existing techniques to teach the skill of writing lacked technology to enhance argumentative writing performance [5]. Without a doubt, online mind mapping through mobile learning has great potential in the teaching and learning of writing in ESL contexts. In this study, the MAMMAT was designed and developed from the 'Appy Pie' application maker for the Android software environment. This online platform allows teachers and course instructors to build free mobile applications without coding. The researchers have been working hard in these past few years to promote mobileoriented apps that can enhance the online experiences of students [6]. Indeed, online mind mapping techniques show great potential as a tool to help diploma students at Malaysian higher educational institutions. This study was designed to determine the effects of the MAMMAT on ESL university students' argumentative writing skill performance with the research question: Does the Mobile-assisted Mind Mapping Technique (MAMMAT) support ESL university students' argumentative writing?

\section{Methodology}

The quasi-experimental method was employed to determine the effects of the MAMMAT in this study. The pre-test, treatment, and post-test were conducted within the limits of ESL university students' teaching and learning experiences. Quantitative data were collected through pre-tests and post-tests, before and after the treatment for the control and the experimental group. The sets of pre and post-tests and the lessons 
for the intervention were examined and scrutinized by two senior English lecturers from the site of study (a Malaysian public university) who are also experts in the teaching of writing. The participants involved in this study were forty-five ESL university students at a public university campus in northern Peninsula Malaysia who took an advanced English writing course for diploma level students. The study was carried out during a fourteen-week full academic semester at the selected university. The population sample for this quasi-experimental design consisted of two groups of university students; the control group was made up of 22 students and the experimental group had 23 students. The control group received conventional instructions via pen and paper, whereas the experimental group was taught using the MAMMAT. Additionally, the control group was taught using paper handouts and typical PowerPoint slides, while the experimental group received treatment using instructions and practice through the MAMMAT mobile application. The students from the control group were trained to create their mind maps using pen and paper whilst the students from the experimental group were trained to create their mind maps using the mind map mobile application. The students practiced the said technique for 4 hours. Then, they practiced writing essays for another 6 hours. After that, both groups were given four argumentative writing tests as an instrument for a pre-test and post-test after the treatment sessions, to compare the mean scores of the two groups at the end of the instructional period. The results of the mean scores were used to determine the effects of the MAMMAT on argumentative writing skills performance. The researchers used descriptive statistics, means and standard deviations to analyze the data. The researchers also used covariance analysis (ANCOVA) to assess any significant differences in the mean scores of the two groups with regard to the argumentative writing output.

\section{Results}

The analysis of data to determine the effectiveness of using the MAMMAT to support ESL university students' argumentative writing skills performance indicated that the treatment had positive effects on their writing performance. Table 1 shows the descriptive statistics of argumentative writing mean scores in the pre-tests and posttests obtained from both groups. Results from the descriptive analysis indicated that the mean scores showed a statistically significant difference between the groups. From Table 1, the pre-test mean scores of the experimental group were 16.80, 17.72, 17.85 and 18.15 , respectively. These were statistically lower than the pre-test mean scores of the control group at 17.20, 18.80 and 18.16 (except for the Test 2 result which was higher than the post-test mean score). 
Table 1. The Descriptive Analysis of Pre and Post-Tests Results of Argumentative Writing

\begin{tabular}{|c|c|c|c|c|}
\hline Argumentative Writing Test & \multicolumn{2}{|c|}{ Pre-test } & \multicolumn{2}{c|}{ Post-test } \\
\hline & $\boldsymbol{M}$ & $\boldsymbol{S . D}$ & $\boldsymbol{M} . \boldsymbol{D}$ \\
\hline \multicolumn{5}{|c|}{ Control Group (n=22) } \\
\hline Test 1 & 17.20 & 2.14 & 17.84 & 2.32 \\
\hline Test 2 & 17.20 & 2.25 & 17.39 & 2.06 \\
\hline Test 3 & 18.80 & 2.28 & 17.07 & 2.23 \\
\hline Test 4 & 18.16 & 3.14 & 18.87 & 1.91 \\
\hline \multicolumn{5}{|c|}{ Experimental Group (n=23) } \\
\hline Test 1 & 16.80 & 1.79 & 19.67 & 1.53 \\
\hline Test 2 & 17.72 & 1.30 & 19.87 & 1.67 \\
\hline Test 3 & 17.85 & 1.96 & 20.39 & 1.30 \\
\hline Test 4 & 18.15 & 1.81 & 20.46 & 1.30 \\
\hline
\end{tabular}

The results also indicate that the post-test mean scores of the experimental group at $19.67,19.87,20.39$ and 20.46 were statistically higher than the post-test mean scores of the control group at 17.84, 17.39, 17.07 and 18.87. The results show that the students who used the MAMMAT attained higher marks in their argumentative writing tests compared to the students who used the conventional method. Therefore, the results of this analysis revealed that the use of the MAMMAT could improve argumentative writing performance.

Table 2 shows the descriptive statistics of writing mean scores in the experimental group. The results of the post-test mean scores of the experimental group were 19.67, 19.87, 20.39 and 20.46; all statistically higher than the pre-test means scores of the experimental group at $16.80,17.72,17.85$ and 18.15 . The data suggest that the use of the MAMMAT has indeed improved the argumentative writing skills of these university students. ANCOVA analysis was also conducted to test the differences in the results of the treatment group on the increase of mean written scores for both groups by monitoring their argumentative writing's mean pre-test scores.

Table 2. The Descriptive Analysis of Pre-and Post-Test Results of the Experimental Group

\begin{tabular}{|c|c|c|c|c|}
\hline Argumentative Writing Test & \multicolumn{2}{|c|}{ Pre-test } & \multicolumn{2}{c|}{ Post-test } \\
\hline & $\boldsymbol{M}$ & $\boldsymbol{S}$. D & $\boldsymbol{M}$ & $\boldsymbol{S} \boldsymbol{D}$ \\
\hline \multicolumn{5}{|c|}{ Experimental Group (n=23) } \\
\hline Test 1 & 16.80 & 1.79 & 19.67 & 1.53 \\
\hline Test 2 & 17.72 & 1.30 & 19.87 & 1.67 \\
\hline Test 3 & 17.85 & 1.96 & 20.39 & 1.30 \\
\hline Test 4 & 18.15 & 1.81 & 20.46 & 1.29 \\
\hline
\end{tabular}

The descriptive analysis results in Table 3 showed that there was a statistically significant difference between groups, $(p<0.05)$. The results showed that by controlling pre-test mean scores, the use of the MAMMAT could really improve ESL university students' writing achievement in the post-test. 
Table 3. Analysis of Covariance (ANCOVA) Result of Argumentative Writing Test 1

\begin{tabular}{|l|c|c|c|c|c|}
\hline \multicolumn{1}{|c|}{ Source } & Sum of Squares & df & Mean square & F & Sig. \\
\hline Pre-test & 7.39 & 1 & 7.39 & 1.98 & 0.16 \\
\hline Group & 40.58 & 1 & 40.58 & 10.88 & 0.00 \\
\hline Error & 156.61 & 42 & 3.73 & & \\
\hline Total & 16069.00 & 45 & & & \\
\hline
\end{tabular}

$* \mathrm{p}<0.05$

Trend analysis using the plot method in repeated measures ANCOVA test for both tests is shown in Figure 1. Trend analysis of mean comparisons from one pre point to post Writing Test 1 shows not much increase in writing mean score for the experimental group, as compared to an increase in writing mean score for the control group. Nevertheless, the increase in writing mean scores in the control group was more significant compared to the experimental group.

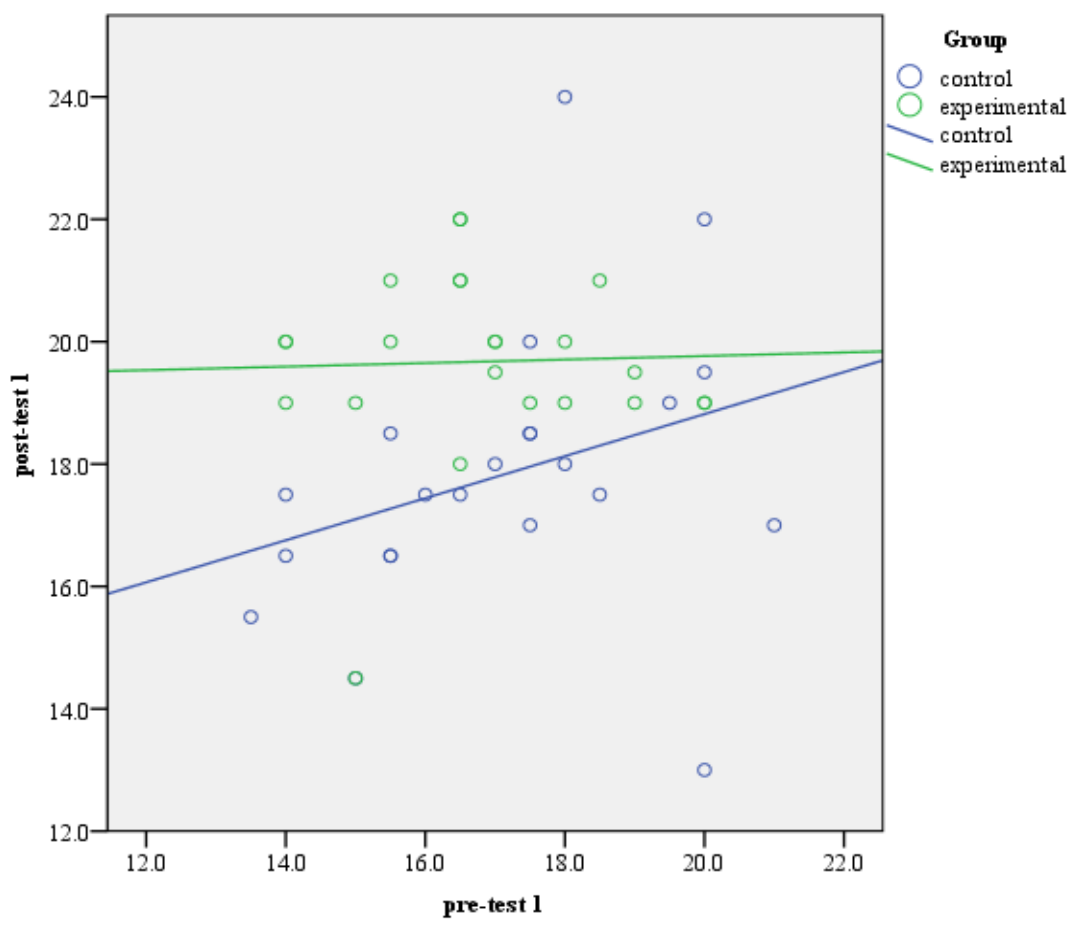

Fig. 1. Between-group comparative Argumentative Writing Test 1 means analysis of trend

The results of the ANCOVA test as shown in Table 4 show that both groups had a statistically significant difference $(\mathrm{p}<0.05)$ in Writing Test 2 . The results indicate that by controlling the pre-test mean scores, the use of the MAMMAT could improve writing performance, as seen in the post-test. 
Table 4. Analysis of Covariance (ANCOVA) Result of Argumentative Writing Test 2

\begin{tabular}{|l|c|c|c|c|c|}
\hline \multicolumn{1}{|c|}{ Source } & Sum of Squares & df & Mean square & F & Sig. \\
\hline Pre-test & 9.81 & 1 & 7.39 & 1.98 & 0.16 \\
\hline Group & 59.96 & 1 & 40.58 & 10.88 & 0.00 \\
\hline Error & 141.26 & 42 & 3.73 & & \\
\hline Total & 15881.75 & 45 & & & \\
\hline
\end{tabular}

$* \mathrm{p}<0.05$

Trend analysis employing the plot method in repeated measures ANCOVA test for both tests is shown in Figure 2. Trend analysis between the means from the pre to the post Writing Test 2 indicate an increase for both groups in writing mean scores from pre to post writing mean scores. However, the increase in writing mean scores in the experimental group was more significant, which suggests that writing test scores improved after the treatment.

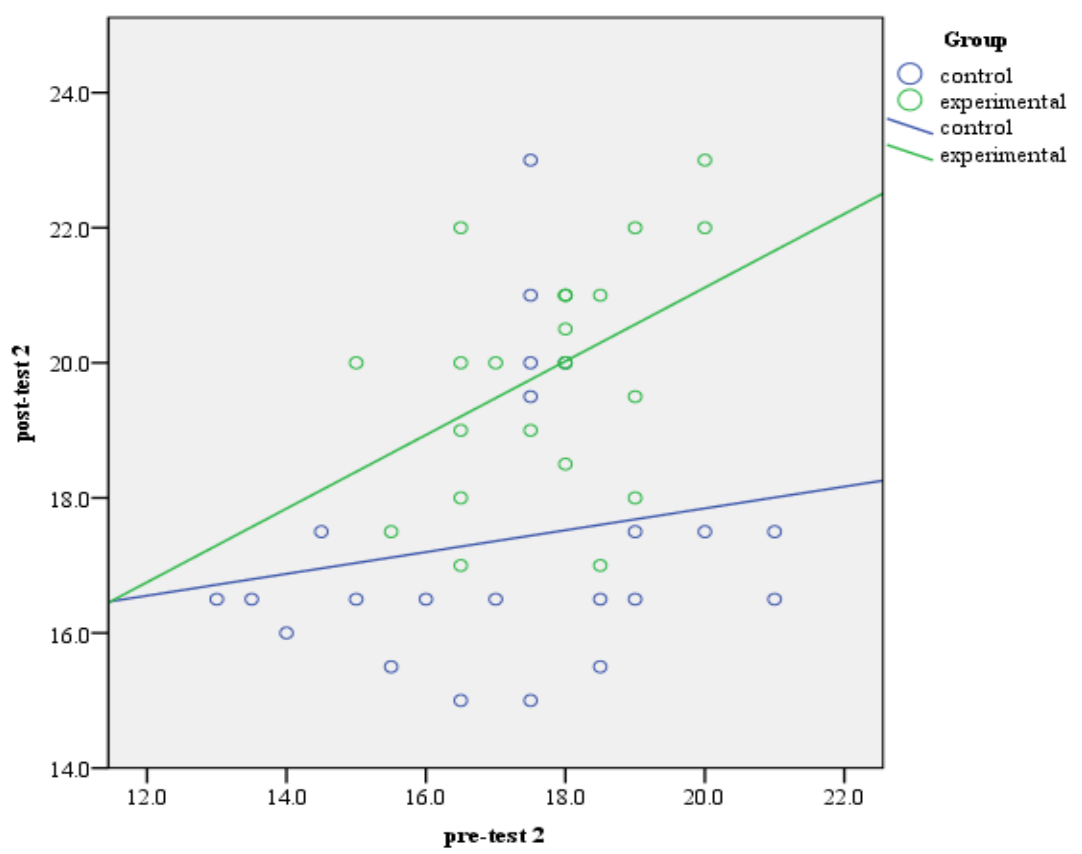

Fig. 2. Between-group comparative Argumentative Writing Test 2 means analysis of trend

Based on the analysis in Table 5, the results of ANCOVA indicate that there was a significant difference between groups with $\mathrm{p}<0.05$. The results illustrate that by controlling pre-test mean scores, the use of the MAMMAT could improve writing performance in the post-test. 
Table 5. Analysis of Covariance (ANCOVA) Result of Argumentative Writing Test 3

\begin{tabular}{|l|c|c|c|c|c|}
\hline \multicolumn{1}{|c|}{ Source } & Sum of Squares & df & Mean square & F & Sig. \\
\hline Pre-test & 17.16 & 1 & 17.16 & 5.81 & 0.02 \\
\hline Group & 139.28 & 1 & 138.28 & 47.19 & 0.00 \\
\hline Error & 123.97 & 42 & 2.96 & & \\
\hline Total & 16113.75 & 45 & & & \\
\hline
\end{tabular}

$* \mathrm{p}<0.05$

Trend analysis utilizing the plot method in repeated measures ANCOVA test for both tests is illustrated in Figure 3. Trend analysis of comparisons between the means from the pre to the post Writing Test 3 shows an increase for both groups in writing mean scores from pre to post writing mean scores. From the perspective of mean value comparisons, both increases in writing mean scores were not too different between the two groups.

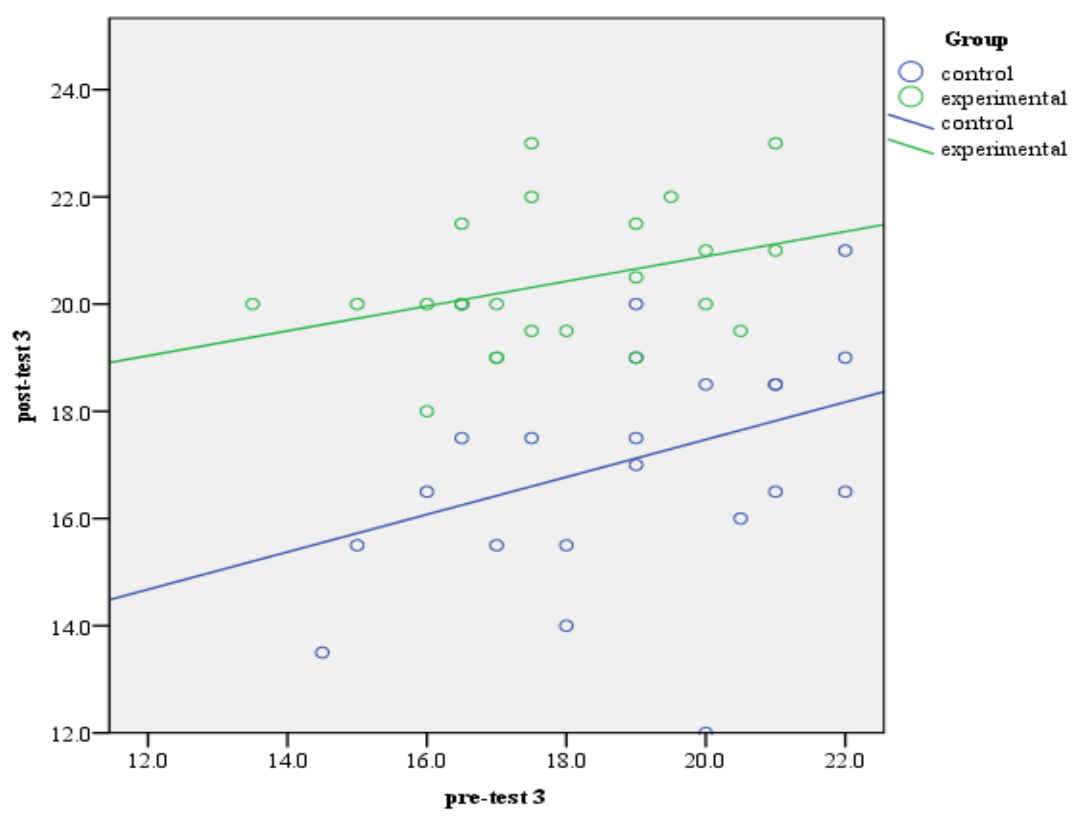

Fig. 3. Between-group comparative Argumentative Writing Test 3 means analysis of trend

The findings of ANCOVA as shown in Table 6 show that there is a statistically significant difference between groups $(p<0.05)$. These results show that by controlling pre-test mean scores, the use of the MAMMAT could improve writing achievement in the post-test. 
Table 6. Analysis of Covariance (ANCOVA) Result of Argumentative Writing Test 4

\begin{tabular}{|l|c|c|c|c|c|}
\hline \multicolumn{1}{|c|}{ Source } & Sum of Squares & df & Mean square & F & Sig. \\
\hline Pre-test & .023 & 1 & 0.23 & 0.009 & 0.93 \\
\hline Group & 27.72 & 1 & 27.72 & 10.31 & 0.00 \\
\hline Error & 112.90 & 42 & 2.69 & & \\
\hline Total & 17585.00 & 45 & & & \\
\hline
\end{tabular}

* $\mathrm{p}<0.05$

Trend analysis with the plot method in repeated measures ANCOVA test for both tests (pre-test and post-test) is illustrated in Figure 4. Trend analysis of comparisons between the means from the pre to the post Writing Test 4 shows an increase in writing mean scores for the experimental group compared to the decline in writing mean scores for the control group.

However, only the experimental group shows a significant increase in writing mean score. In addition, the results also indicate that there is a statistically significant difference for both groups in their writing mean scores. From the results, it can also be concluded that the experimental group had performed far better than the control group, overall.

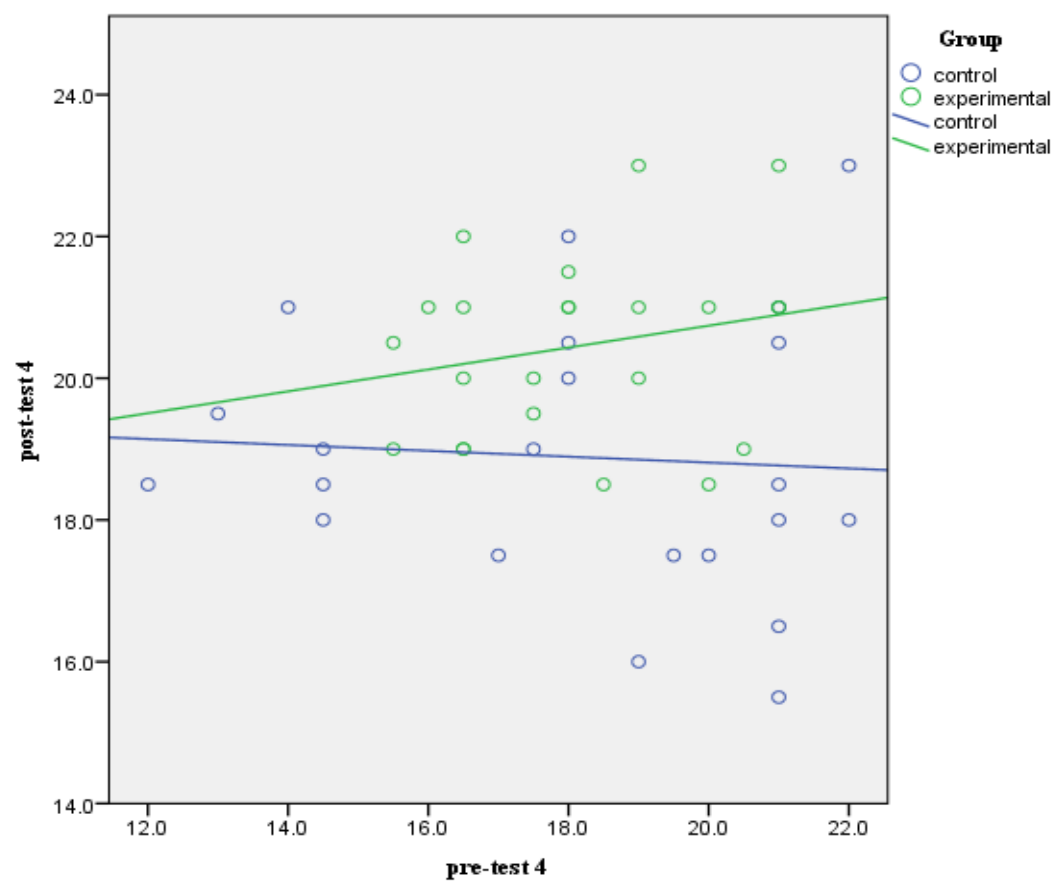

Fig. 4. Between-group comparative Argumentative Writing Test 4 means analysis of trend 


\section{Discussion}

The findings of this study can be summarized as follows. First and foremost, the use of the MAMMAT as a mobile application can realistically support ESL university students' argumentative writing skills development. Based on the results of the study, the university students who used the MAMMAT performed better in argumentative writing tests than students who merely used traditional pen and paper techniques. Besides that, there was a significant effect on the experimental group as compared to the control group. Novel technological elements in the MAMMAT could enhance the students' writing performance as compared to the control group. The learning contents of the MAMMAT helped the students to learn and improve their argumentative writing skills. Additionally, the students also developed an interest in mobile learning.

These findings seem to support previous studies that suggest learning content management subsystem are one of the essential components for the mobile learning system [7]. Furthermore, it was found that mobile technologies help learners to access language learning materials easily [8], and this had a knock-on effect to increase interests in language learning. Another study confirms this, as their findings showed that the application of mobile technologies in teaching increases student focus, develops students' skills and nurture positive acceptance of mobile learning [9]. Similarly, the use of mobile-based technological tools in writing activities has the potential to improve actual writing performance. Hence, university instructors need to encourage their students to use mobile devices widely and frequently in the teaching and learning process. Moreover, the findings indicate that Malaysian university students were active and autonomous, and they had positive results towards the use of mobile technology in their learning [10]. To this end, it is recommended that mobile learning should start at an early age in the Malaysian context. In Greece, for instance, pre-service teachers are asked to use mobile devices in teaching natural sciences from kindergarten level. This effort resulted in the popularity, acceptance, and wider use of mobile technologies for teaching and learning, even for very young students $[11,12]$. Hence, further research should be more focused on innovative types of interactive technologies [13].

\section{Conclusion}

This study confirms that the MAMMAT is effective in supporting ESL university students' argumentative writing performance. The tool affords significant contributions to enhance the skill of writing for university students in Malaysia. Therefore, university instructors must take further efforts to encourage students to use mobile devices to support the teaching and learning of writing at this level. In addition, further research should be carried out to gain more insights with regards to the reproduction of the present study to propel university students' mobile learning practices into the $21^{\text {st }}$ century. 


\section{$6 \quad$ References}

[1] Papadakis, S. (2018). Evaluating pre-service teachers' acceptance of mobile devices with regards to their age and gender: a case study in Greece. International Journal of Mobile Learning and Organisation, 12(4): 336-352. https://doi.org/10.1504/ijmlo.2018.095 $\underline{130}$

[2] Mueangpud, A., Khlaisang, J., \& Koraneekij, P. (2019). Mobile Learning Application Design to Promote Youth Financial Management Competency in Thailand. International Journal of Interactive Mobile Technologies, 13(2): 19-38. https://doi.org/10. 3991/ijim.v13i12.11367

[3] Meftah, C., Retbi, A., Bennani, S., \& Idrissi, M. K. (2019). Mobile Serious Game Design using User Experience: Modeling of Software Product Line Variability. International Journal of Emerging Technologies in Learning, 14(23): 55-66. https://doi.org/10. 3991/ijet.v14i23.10899

[4] Adnan, A. H. M., Karim, R. A., Tahir, M. H. M., Kamal, N. N. M., \& Yusof, A. M. (2019). Education 4.0 Technologies, Industry 4.0 Skills and the Teaching of English in Malaysian Tertiary Education. Arab World English Journal, 10(4): 330-343. https://doi.org/10. 24093/awej/vol10no4.24

[5] Rafidah Abd Karim, Airil Haimi Mohd Adnan, Mohd Haniff Mohd Tahir, Mohd Hafiz Mat Adam, Noorzaina Idris \& Izwah Ismail. (2020). The Application of Mobile Learning Technologies at Malaysian Universities Through Mind Mapping Apps for Augmenting Writing Performance. Advances in Science Technology and Engineering Systems Journal, 5(3):510-517. https://doi.org/10.25046/aj050363

[6] Rafidah Abd Karim, Abdul Ghani Abu, Airil Haimi Adnan \& Astri Dwi Jayanti Suhandoko, The use of mobile technology in promoting Education 4.0 for Higher Education, Advanced Journal of Technical and Vocational Education, 2 (3): 34-39. DOI: 10.26666/rmp.ajtve.2018.3.6

[7] Todoranova, L., Nacheva, R., \& Sulov, V. (2020). A Model for Mobile Learning Integration in Higher Education Based on Students' Expectations. International Journal of Interactive Mobile Technologies, 14(11): 171-182. https://doi.org/10.3991/ijim.v14i11.13711

[8] A. Sherine., M. M. Sastry, \& Seshagiri, A. V. S. (2020). Improving Second Language Speaking and Pronunciation Through Smartphones. International Journal of Interactive Mobile Technologies, 14(11): 280-287. https://doi.org/10.3991/ijim.v14i11.13891

[9] El-Sofany, H., \& El-Haggar, N. (2020). The Effectiveness of Using Mobile Learning Techniques to Improve Learning Outcomes in Higher Education. International Journal of Interactive Mobile Technologies, 14(8): 4-18. https://doi.org/10.3991/ijim.v14i08.13 $\underline{125}$

[10] R. A. Karim., A. H. M. Adnan., M. S. A. M. Salim., S. Kamarudin., \& A. Zaidi., (2020). Education Innovations through Mobile Learning Technologies for the Industry 4.0 Readiness of Tertiary Students in Malaysia. IOP Conference Series Material Engineering, 917. https://doi.org/10.1088/1757-899x/917/1/012022

[11] Kalogiannakis, M., \& Papadakis, S. (2019). Evaluating pre-service kindergarten teachers' intention to adopt and use tablets into teaching practice for natural sciences. International Journal of Mobile Learning and Organisation, 13(1): 113-127. https://doi.org/10.1504/ ijmlo.2019.096479

[12] Papadakis, S., \& Kalogiannakis, M. (2017). Mobile educational applications for children: What educators and parents need to know. International Journal of Mobile Learning and Organisation,11(3):256-277. https://doi.org/10.1504/ijmlo.2017.085338. 
[13] Dorouka, P., Papadakis, S., \& Kalogiannakis, M. (2020). Tablets and apps for promoting robotics, mathematics, STEM education and literacy in early childhood education. International Journal of Mobile Learning Organisation, 14(2): 255-274. https://doi.org/10.1504/ijmlo.2020.10026334

\section{$7 \quad$ Authors}

Rafidah Abd Karim is a senior lecturer in the Academy of Language Studies at Universiti Teknologi MARA Perak Branch, Tapah Campus, Malaysia. She holds a PhD in TESL. Her research interest is mainly on mobile learning, mind mapping, e-learning and TESL. Email: feida16@uitm.edu.my

Airil Haimi Mohd Adnan holds a PhD in Applied Language Studies (Applied Linguistics). He is a Senior Lecturer and Deputy Dean of APB Student Affairs, Universiti Teknologi MARA, Selangor, Malaysia.

Abdul Ghani Abu is a teacher-trainer, curriculum developer, $\mathrm{PhD}$ holder and an Assoc. Prof. in TESL at the English Department of Faculty of Languages and Communication, Universiti Pendidikan Sultan Idris, Perak, Malaysia. His research areas include learning styles and strategies, post-colonial literature, comparative literature, Malaysian Literature in English and pedagogical syntax.

Noorzaina Idris is a $\mathrm{PhD}$ in Applied Linguistics, a TESL senior lecturer in the Faculty of Education, Universiti Teknologi MARA Puncak Alam Branch, Selangor, Malaysia.

Izwah Ismail is a senior lecturer at Electrical Engineering Department and is the current Deputy Director Academic of Politeknik Ungku Omar, Ipoh, Perak, Malaysia. She holds a $\mathrm{PhD}$ in Electrical Engineering from Universiti Teknologi MARA, Malaysia.

Article submitted 2020-02-29. Resubmitted 2020-12-23. Final acceptance 2020-12-23. Final version published as submitted by the authors. 